\title{
Implementasi Bimbingan Penggunaan Komputer terhadap UNBK Kelas 9 SMP Muhammadiyah 7 Eromoko, Wonogiri
}

\author{
Naufal Ishartono ${ }^{1}$, Trisna Aditya. $\mathbb{W}^{2}$, Nurul Afifah ${ }^{3}$, Ika Wulansari M. K ${ }^{4}$, Annisa Apriliaddina ${ }^{5}$, \\ Nevha Kharisma P.P ${ }^{6}$, Syiffa Ghaisani V. ${ }^{7}$, Tunjung Nala Puti ${ }^{8}$, Rochmat Agung Nurdianzah ${ }^{9}$, MB \\ Dian K. $\mathrm{H}^{10}$

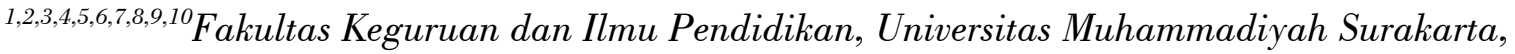 \\ Indonesia
}

\section{INFORMASI ARTIKEL}

Histori Artikel:
Submit: 28 April 2020
Revisi: 30 Agustus 2020
Diterima: 1 September 2020
Publikasi: 3 September 2020
Periode Terbit: Desember 2020

\section{Kata Kunci:}

berbasis komputer,

implementasi,

pendidikan,

ujian nasional

\section{Correspondent Author:}

Naufal Ishartono

Fakultas Keguruan dan Ilmu Pendidikan

Universitas Muhammadiyah Surakarta,

Indonesia

Email:naufal.ishartono@ums.ac.id

\begin{abstract}
ABSTRAK
Ujian Nasional Berbasis Komputer adalah sebuah terobosan yang dilakukan oleh Pemerinta Indonesia dalam meningkatkan mutu ujian di Indonesia. Adapun masalah yang terjadi adalah seberapa siapkah siswa dalam menghadapi ujian nasional menggunakan computer, oleh karena itu diperlukan sebuah pelatihan penyesuaian kepada siswa untuk terbiasa dengan computer sebagai persiapan UNBK. Tujuan pengabdian ini adalah untuk meningkatkan pemahaman siswa dalam menggunakan komputer untuk mempersiapkan UNBK. Metode pengabdian yang digunakan adalah dengan menggunakan bimbingan secara langsung kebpada siswa. Adapaun hasil dari program pengabdian masyarakat ini adalah secara tidak langsung implementasi bimbingan penggunaan komputer pada siswa kelas 9 SMP Muhammadiyah 7 Eromoko tersebut dapat membantu siswa agar lebih mahir dalam mengoperasikan komputer sebagai basis dalam UNBK. Siswa lebih mudah beradaptasi dengan alat alat komputer dan tidak merasa kebingungan dengan peralatan komputer yang disediakan.
\end{abstract}

\section{Pendahuluan}

Perkembangan teknologi adalah sebuah keniscayaan yang harus diahadapi oleh semua orang saat ini. Khususnya di dalam kondisi dimana dunia saat ini sedang dilanda pandemik Coronavirus Disease 2019 (Covid19), peran teknologi menjadi lebih vital. Physical distancing menjadi sebuah norma baru untuk setiap manusia untuk saling berkomunikasi. Hal ini bertujuan untuk memperlambat jumlah penderita Covid-19 yang menurut laporan World Health Organization (WHO) per tanggal 19 Agustus 2020 jumlah korban meninggal karena Covid-19 di Indonesia telah mencapai 6.346 orang atau 4\% dari total penderita Covid-19 di Indonesia (Organization World Health, 2020). Dari kondisi inilah peran teknologi menjadi sangat vital.
Dalam perkembangannya, ilmu pengetahuan dan teknologi diyakini sebagai budaya baru yang meningkatkan dalam produktivitas kerja manusia. Dikatakan demikian karena terciptanya teknologi akan mempermudah pekerjaan manusia, meningkatkan efektivitas dari kerja manusia, sehingga lebih produktif dalam mengerjakan sesuatu.Teknologi mampu merubah segala hal yang tak bisa tersentuh menjadi terjamah (Sunandar, 2019).

Teknologi adalah bagian penting dari seluruh aspek pekerjaan manusia tak terkecuali dalam bidang pendidikan. Pendidikan menjadi sektor yang sangat utama dan strategis. Hal tersebut karena sumber daya manusia yang berpendidikan dapat memberikan pengaruh pada bidang lainnya (Ula, 2017). Pendidikan menjadi 
seperti SMP Muhammadiyah 7 Eromoko yang berada di Kabupaten Wonogiri. Pada dasarnya SMP Muhammdiyah 7 Eromoko sudah sekolah berbasis komputer, namun ada beberapa kendala yang membuat sekolah berbasis teknologi ini kurang mampu bersaing dengan sekolah lain. Kendala tersebut diantaranya adalah kurangnya pengetahuan tentang penggunaan perangkat komputer, serta keterbatasan perangkat komputer yang ada di sekolah tersebut.

Berdasarkan kendala yang ada, peneliti merinci beberapa rumusan masalah. Rumusan masalah tersebut yaitu bagaimana menambah pemahaman perserta didik mengenai dasar-dasar penggunaan komputer. Sebelum menguasai teknologi komputer sangat penting bagi peserta didik mengenal dan memahami dasar-dasarnya. Selain itu, bagaimana bimbingan pengunaan computer dalam mempersiapkan UNBK dan implementasinya. Sangat perlu bagi peserta didik untuk mendapat bimbingan ataupun sosialisasi terkait UNBK. Karena banyak dari siswa yang masih kurang memahami benar sistematika UNBK. Keikutsertaan bimbingan TIK dalam mempersiapkan UNBK menjadi kewajiban pembimbingan dan fasilitator untuk peserta didik (Elmasari, 2017).

Berdasarkan pemaparan diatas penulis tertarik untuk meneliti implementasi bimbingan kepada peserta didik mengenai penggunaan computer dalam mempersiapkan UNBK. Hal ini penulis pilih agar semua peserta didik lebih siap dan mampu dalam menghadapi UNBK nantinya. Penelitian tersebut berjudul Implementasi Bimbingan Penggunaan Komputer terhadap UNBK Siswa Kelas IX SMP Muhammadiyah 7 Eromoko Wonogiri.

\section{Metode Pelaksanaan}

Pengabdian ini menggunakan pendekatan kualimenjadi suatu alternatif untuk mengatasi kelemahan pada ujian nasional berbasis kertas (Negara, 2017).

Ujian nasional berbasis kertas dinilai memiliki banyak kelemahan dari pembuatan soal hingga penyebaran soal-soal tersebut. Berubahnya sistem ujian nasional juga dapat membantu mengurangi pemakaian kertas. Diadakannya ujian nasional berbasis komputer ini juga dapat menjadi solusi untuk mencegah kebocoran soal dan kecurangan sehingga hasil ujian dapat dipercaya (Cendhrasari, 2019)

Berbagai sekolah di Indonesia kini sudah menggunakan pembelajaran berbasis teknologi, tak terkecuali sekolah yang berada jauh dari Perkotaan, tatif dengan metode bimbingan langsung dan partisipasi penuh. Adapun subjek pelatihan ini adalah siswa-siswa kelas IX SMP Muhammadiyah 7 Eromoko. Pelatihan dilakukan selama tiga hari. Proses pengabdian meliputi pengenalan proses UNBK, pemberian modul pelatihan kepada siswa, pelatihan kepada siswa, pendampingan, dan ujicoba.

\section{Hasil Pelaksanaan dan Pembahasan}

Salah satu faktor yang dapat memengaruhi mutu pendidikan yaitu penggunaan teknologi informasi dan komunikasi. Sehingga pemerintah memiliki kewajiban 
untuk melengkapi layanan pendidikan yang menunjang penguasaan teknologi informasi dan komunikasi. Siswasiswa kelas IX SMP Muhammadiyah 7 Eromoko sudah mulai mendekati hari-hari UNBK.

\section{Isu Isu Kebijakan Pelaksanaan UNBK}

1. Kesiapan Siswa Melaksanakan UNBK Kesiapan diatas dapat diartikan sebagai kondisi dari fisik, mental, emosional yang baik, kemudian didukung dengan pengetahuan dan keterampilan untuk menanggapi sebuah kejadian atau melakukan suatu kegiatan. Salah satu faktor yang dapat mempengaruhi belajar diantaranya, yaitu faktor internal. Faktor internal merupakan faktor yang berasal dari diri peserta didik sendiri dan meliputi dua aspek, yakni 1) aspek fisiologi dan, 2) aspek psikologi, ada beberapa komponen yang dapat mempengaruhi psikologis atau mental peserta didik diantaranya yaitu kecerdasan/pengetahuan, minat, motivasi, sikap dan bakat.

2. Kesiapan Sekolah Melaksanakan UNBK Kesiapan sekolah hal ini adalah tingkat kesediaan suatu satuan pendidikan dalam melaksanakan kebijakan-kebijakan yang diturunkan oleh pemerintah, seperti halnya pelaksanaan ujian nasional berbasis komputer. Sekolah harus mampu menyediakan semua fasilitas yang di butuhkan oleh siswa. Kesiapan sekolah menjadi aspek yang sangat penting dimana hal ini dapat mempengaruhi kesiapan siswa, selain itu kesiapan guru serta sarana prasarana juga menjadi aspek yang sangat penting untuk diperhatikan. Peran guru sebagai motivator yang dapat memberi pengaruh yang kuat bagi kesiapan siswa, begitu pula dengan sarana prasarana dengan adanya sarana prasarana yang memadai maka hal ini dapat meningkatkan kesiapan siswa.

Kebijakan pemerintah dalam bidang pendidikan terkhusus dalam aspek evaluasi pendidikan tertuang dalam Peraturan Pemerintah No. 5 Tahun 2015 mengenai pelaksanaan Ujian Nasional Berbasis Komputer (UNBK). Kebijakan ini sejalan dengan kemajuan teknologi di era globalisasi yang semakin meningkat. Sosialisasi mengenai sistem UNBK tidak hanya ditujukan untuk kesiapan sekolah saja yang mendukung Saranan dan prasarana namun juga pada aspek penting yaitu kesiapan siswa.

Siswa kelas IX SMP Muhammadiyah 7 Eromoko merupakan siswa yang telah mengenal beberapa komponen atau hardware komputer. Namun beberapa siswa masih belum mengetahui dengan jelas tentang penggunaan dari bagian bagian komputer yang ada. Sosialisasi yang diberikan kepada siswa melalui pengenalan bagian komputer beserta fungsinya. Selanjutnya siswa dikenalkan beberapa aplikasi microsoft office seperti Ms. World, Ms. Excel, Ms. Power Points maupun aplikasi perangkat lunak lain dalam pengenalan dasar software komputer.

Secara tidak langsung pengenalan terhadap perangkat lunak atau keras komputer tersebut dapat membantu siswa agar lebih mahir dalam mengoperasikan komputer sebagai basis dalam UNBK. Siswa lebih mudah beradaptasi dengan alat alat komputer dan tidak merasa kebingungan dengan peralatan komputer yang disediakan.

Ujian Nasional Berbasis Komputer (UNBK) tidak bisa dilakukan semena-mena dengan sekadar mengadakan dan menjalankannya. Ada juga beberapa persyaratan baik persyaratan bagi sekolahan yang ingin mengadakannya maupun pemerintah yang harus memfasilitasinya dengan baik dan benar, juga harus ada petugas yang berpengalaman dan mumpuni dibidangnya.

Ujian Nasional Berbasis Komputer (UNBK) atau disebut juga Computer Based Test (CBT) merupakan sistem pelaksanaan ujian nasional menggunakan komputer sebagai media untuk melaksanakan ujian. UNBK ini pertama kali diperkenalkan oleh Menteri pendidikan pada tahun 2014 dan kemudian dilaksanakan secara online pada beberapa sekolah. Selanjutnya pada tanggal 26 Januari 2017, Kepala Pusat Penilaian Pendidikan (Puspendik) Kemendikbud menyatakan, berdasarkan data terakhir terdapat 28.380 sekolah yang siap melaksanakan UNBK.

Berdasarkan jumlah tersebut, sekitar 23 ribu sekolah siap menyelenggarakan UNBK di sekolahnya sendiri, sedangkan sisanya sekitar 4.500 sekolah menginduk ke sekolah lain. Tahun 2017 di Aceh besar baru 15 sekolah SMP/MTs yang melaksanakan UNBK. Ada beberapa aspek kriteria yang harus diperhatikan untuk mengukur tingkat kelayakan tersebut diantaranya meliputi ketersediaan infrastruktur, guru dan teknisi yang berkompeten, serta kesiapan mental dari siswa sendiri.

Maka dari itu upaya kita meningkatkan kemampuan penggunaan komputer yang pertama dilakukan yaitu pengenalan perangkat keras dan perangkat lunak komputer, dan juga motivasi menjelang Ujian Nasional Berbasis Komputer berlangsung. Dari 
e-ISSN 2716-0327

doi: 10.23917/bkkndik.v2i2.10777

pengenalan perangkat keras dan perangkat lunak ini sendiri di lakukan oleh Mahasiswa KKN.

Setelah seminggu program KKN berjalan kami memulai analisis ini dengan memberikan materi kepada siswa kelas IX SMP Muhammadiyah 7 Eromoko mengenai perangkat keras dan perangkat lunak komputer. Pemberian materi ini di lakukan sekali waktu dengan sistem mengumpulkan siswa kelas IX di jadikan satu ruangan yaitu di aula sekolah. Di samping pengenalan komputer tujuan kami mengumpulkan siswa kelas IX menjadi satu agar siswa satu sama lain dapat berinteraksi mengenai persiapan UNBK.

Materi yang diberikan diantaranya berupa cara menghidupkan dan mematikan komputer, penggunaan dasar dasar komputer seperti Ms. World, Ms. Excel, Ms. Power Points dan tentunya materi lisan mengenai simulasi ujian nasional. Selain siswa kelas IX dapat menggunakan komputer untuk UNBK tapi siswa juga dapat mengakses aplikasi dasar komputer yang mana pada dasarnya siswa lulusan SMP harus paham aplikasi dasar komputer.

Satu minggu pemberian materi berlangsung pelatihan komputer pada siswa di lanjutkan simulasi penggunaan komputer yang mana dilakukan bergilir karena melihat fasilitas sekolah yang hanya menyediakan 10 komputer untuk simulasi UNBK. Simulasi ini sendiri dilaksanakan oleh sekolah yang mana mahasiswa KKN hanya mendampingi.

Simulasi ini dilaksanakan berkala setiap minggu melihat banyaknya siswa yang belum memahami kinerja komputer. Dalam simulasi ini siswa mempraktikan penggunaan komputer untuk UNBK. Pada dasarnya materi yang di berikan berperan penting dalam simulasi UNBK karena banyaknya siswa yang belum mengetahui bagaimana penggunaan komputer. Sehingga motivasi dan pemberian materi ini mendorong siswa untuk lebih mudah mengenal dan menggunakan komputer.

Perbandingkan dengan sebelum diadakan pelatihan banyak siswa yang masih belum tahu bagaimana dan seperti apa komputer di gunakan. Perbandingan ini dilihat dari pengetahuan dan survei siswa yang bisa menggunakan komputer dan siswa yang sudah bisa menggunakan komputer. Jika di lihat dari persentase siswa yang belum bisa menggunakan komputer dan yang sudah bisa menggunakan komputer adalah $30 \%$ banding $70 \%$. Dan survei setelah pelatihan komputer lebih banyak siswa yang sudah bisa menggunakan komputer yaitu $80 \%$ banding 20\%. Hasil tersebut di hitung sampai 29 februari
2020, dan yang mana UNBK di laksanakan pada 24 april 2020 .

\section{Simpulan}

Pengenalan beberapa komponen atau hardware computer pada siswa kelas IX SMP Muhammadiyah 7 Eromoko merupakan salah satu hal yang diperlukan guna menghadapi Ujian Nasional Berbasis Komputer (UNBK). Pengenalan tersebut dilakukan dengan cara memberikan sosialisasi kepada siswa melalui pengenalan bagian komputer beserta fungsinya. Selanjutnya, siswa dikenalkan beberapa aplikasi microsoft office seperti Ms. World, Ms. Excel, Ms. Power Points maupun aplikasi perangkat lunak lain dalam pengenalan dasar software komputer.

Upaya implementasi bimbingan penggunaan komputer pada siswa kelas 9 SMP Muhammadiyah 7 Eromoko tersebut dapat membantu siswa agar lebih mahir dalam mengoperasikan komputer sebagai basis dalam UNBK. Siswa lebih mudah beradaptasi dengan alat alat komputer dan tidak merasa kebingungan dengan peralatan komputer yang disediakan.

\section{Daftar Pustaka}

Elmasari, Y. 2017. Pengaruh Bimbingan Guru Teknik Informatika Terhadap Kesiapan Siswa Dalam Pelaksanaan Ujian Nasional Berbasis Komputer. JIPI. Vol. 02., No. 02., Desember 2017., Hal. 128132.

Flick, U., Kardorff, E. V., \& Steinke, I. (2004). A Companion to Qualitative Research. (SAGE Publi). London.

Negara, H. R. P., Santosa, F. H., Bahri, S. 2017. Peningkatan Kompetensi Ict Guna Simulasi Unbk Siswa Mts Nurul Ihsan Kecamatan Jonggat Kabupaten Lombok Tengah. Jurnal Masyarakat Mandiri. Vol.1., No. 1., Hal 1-9.

Organization World Health. (2020). Coronavirus Dsease 2019 (Covid-19): Situation Report - 21 in Indonesia. Retrieved from https:/www.who.int/docs/defaultsource/searo/indonesia/who-situation-report2146ed3282e0f34f1d9dbda4971c5a2a9d.pdf?sfvrs $\mathrm{n}=21 \mathrm{e} 7 \mathrm{~d} 02 \_2$.

Sugiyono. (2013). Metode Penelitian Kuantitatif, Kualitatif, dan R\&D. Bandung: Alfabeta.

Santi, M., Prajana, A. 2018. Analisis Implementasi Ujian Nasional Berbasis Komputer dengan Ujian Berbasis Kertasdi SMPN 3 Ingin Jaya Kabupaten Aceh Besar. Jurnal Pendidikan TeknologiInformasi.Vol. 2., No. 2., Oktober 2018., Hal. 84-91. 
Suhana, C. (2014). Konsep Strategi Pembelajaran. Bandung: Refika Aditama. penduduk miskin. Jurnal Psikologi Sosial, 14(1), 11-24.

Sunandar, D., Vindua, R., Nurhayati., Putri, S. R., Muiz, A. 2020. Pelatihan Sistem Komputerisasi untuk Menghadap iUNBK 2020 Pada Santri - Santridi PondokPesantren Al Inayah. JAMAIKA: Jurnal Abdi Masyarakat Program Studi Teknik Informatika. Vol. 1., No. 1., Hal. 26-32.

Syah, Muhibbin. 2013. Psikologi Pendidikan. Bandung: PT. Remaja Rosdakarya. "5.667 Siswa SMP/Mts Ikut Ujian Nasional di Aceh Besar." [Online]. Available: http:/humas.acehbesarkab.go.id/5-667-siswa- smpmts-ikut-ujian-nasional-diaceh-besar/. [Accessed: 04-Aug-2017].

Ula, S. M., Nawangsari, E. R. 2017. Implementasi Ujian Nasional Berbasis Komputer (Computer Based Test, CBT) di SMP Negeri 1 SidoarjoKabupatenSidoarjo. Jurnal Dinamika Governance FISIP UPN Veteran Jatim. Vol. 7., No. 1., April 2017, Hal. 1-12.

W.O,Chendrasari., Natalia, C., Inderawati, MM.W. 2019.Pendampingan Persiapan Ujian Nasional Berbasis Komputer (UNBK) Mtss Nurul Huda, Desa Sampora, Banten. Jurnal Bakti Masyarakat Indonesia. Vol. 2, No. 1, Mei 2019, Hal. 155-161. 